\title{
Pengaruh Akupunktur Jin's 3 Needle Dalam Menurunkan Intensitas Nyeri Penderita Nyeri Punggung Bawah Di Balai Kesehatan Tradisional Sehat Harmoni Indonesia Malang
}

\section{The Influence Of Jin's 3 Needle Acupuncture Toward Decrease Of Pain Intensity Of Low Back Pain Patients In The Traditional Health Center Harmony Indonesia Malang}

\author{
Ikhwan, Abdullah ${ }^{1 *}$, Amal Prihatono ${ }^{2}$ \\ 1,2, Program Studi Akupunktur Politeknik Kesehatan RS dr. Soepraoen Malang \\ *Corresponding author \\ Email: Ikhwana03@gmail.com
}

Keyword :

Acupuncture,

Jin's 3 needle,

Pain Intensity,

Low Back Pain

\begin{abstract}
Background: Low Back Pain (LBP) is one of the health problems in the world and causes the restriction of activities and absence of employment. The Jin's 3 needles that use to reduce LBP have been the world's concern. From 291 studies, LBP is the highest contributor to global disability and about $80 \%$ of workers have LBP. Every year in Indonesia 14-45\% of adults have LBP. A new case of LBP in Malang in 2012 was 330 people (18.7\%), 2013 were 408 people (20.9\%). The aim to analyze the influence of Jin's 3 needle acupuncture toward the decrease of pain intensity of LBP patients. Methods: used pre-experimental design with pre-post test design. The population was all people who LBP and to visit the Traditional Health Center Harmony Indonesia Malang, the sample was 15 people, total sampling, using observation sheets (Bourbanis scale), acupuncture needle, data analysis paired t-test with SPSS v.21. The results: that before therapy of Jin's 3 Needle of 15 patients of LBP i.e 4 people (27\%) less pain, 8 people (53\%) middle pain, 3 people (20\%) highly pain, after therapy for 2 months, frequency third per weeks, there was a decrease of pain intensity of LBP that 2 people (13\%) no pain, 9 people (60\%) less pain, 4 people (27\%) highly pain, $p=0.00<\alpha$ 0.05. The conclusion: that acupuncture therapy Jin's 3 Needle can decrease of pain intensity of LBP. Acupuncture therapy can be an alternative method of non-pharmacology to decrease $L B P$.

\section{A B S T R A K}

A B S T R A K
Latar Belakang Nyeri punggung bawah (Low Back Pain/ LBP) merupakan masalah
kesehatan dunia dan menyebabkan pembatasan aktivitas serta ketidakhadiran kerja.
Akupunktur Jin's 3 needle digunakan untuk mengatasi LBP telah menjadi perhatian
dunia. Sekitar 291 penyakit yang diteliti, LBP merupakan penyumbang terbesar
kecacatan global dan sekitar $80 \%$ pekerja di Dunia pernah mengalami LBP. Setiap tahun
di Indonesia 14-45\% orang dewasa menderita LBP. Kasus baru LBP di Malang pada
tahun 2012 terdapat 330 orang (18,7\%), tahun 2013 terdapat 408 orang (20,9\%). Tujuan
penelitian menganalisis pengaruh akupunktur Jin's 3 needle terhadap penurunan
intensitas LBP di Balai Kesehatan Tradisional Sehat Harmoni Indonesia Malang. Metode
Penelitian pre-eksperimental design dengan jenis pretest-posttest design. Populasi semua
penderita LBP yang berkunjung ke Balai Kesehatan Tradisional Sehat Harmoni Indonesia
Malang, sampel 15 orang, teknik total sampling, instrumen menggunakan lembar
observasi skala nyeri Bourbanis, jarum akupunktur, analisis data paired sample t test
menggunakan SPSS v.21. Hasil penelitian sebelum diberikan terapi akupunktur Jin's 3
Needle diketahui intensitas nyeri dari 15 penderita nyeri punggung bawah meliputi 4
orang nyeri ringan (27\%), 8 orang nyeri sedang (53\%), 3 orang nyeri berat (20\%), setelah
diberikan terapi selama 2 bulan, frekuensi 3 kali seminggu diketahui terdapat penurunan
intensitas nyeri penderita LBP meliputi tidak nyeri sebanyak 2 orang (13\%), nyeri ringan
\end{abstract}

Kata kunci :

Akupuntur,

Jin's 3 needle,

Intensitas Nyeri,

Nyeri Punggung 
sebanyak 9 orang (60\%), nyeri sedang sebanyak 4 orang (27\%). Hasil uji Paired t test diperoleh $\mathrm{p}=0.00<\alpha$ 0.05. Kesimpulan Terapi akupunktur Jin's 3 Needle dapat menurunkan intensitas nyeri LBP. Terapi akupunktur dapat digunakan sebagai metode alternatif non farmakologi untuk mengurangi keluhan LBP.

\section{PENDAHULUAN}

Nyeri punggung bawah (Low Back Pain/ LBP) merupakan sejenis penyakit yang gejala utamanya adalah nyeri pada satu atau dua sisi pinggang (punggung bawah) dan merupakan penyakit yang berhubungan dengan musculoskeletal. ${ }^{1,2}$. Nyeri punggung bawah menjadi masalah kesehatan dunia dan menjadi penyebab pembatasan aktivitas fisik serta ketidakhadiran kerja. $^{3}$

Berdasarkan data The Global Burden of Disease 2010 Study (GBD 2010) sekitar 90\% nyeri punggung bawah akut dapat sembuh dengan sendirinya, sedangkan $10 \%$ sisanya menjadi kronis. ${ }^{3}$ Selain itu, diperkirakan sekitar $70-85 \%$ penduduk pernah mengalami nyeri punggung bawah dan merupakan penyebab kedua kehilangan jam kerja setelah sefalgia. ${ }^{4}$ Data prevalensi nyeri punggung bawah mengalami peningkatan selama dua dekade terakhir dengan prevalensi rata-rata 19,4\% secara global. ${ }^{5}$ Data prevalensi nyeri punggung bawah berdasarkan jenis kelamin yaitu pada laki-laki sebesar 18,2\% dan pada wanita sebesar $13,6 \% .^{6}$

Penyebab nyeri punggung bawah karena atau yang disebut dengan kekakuan otot/ spasme musculosceletal, adanya trauma luar, atau karena ginjal defisit (sebuah sindrom menurut ilmu Oriental Medicine yang menyatakan adanya kekurangan substansi vital dalam organ ginjal sehingga menimbulkan ketegangan otot daerah punggung bawah). ${ }^{1}$ Hal tersebut terjadi karena berbagai faktor yang memicu timbulnya nyeri punggung bawah antara lain posisi duduk, lama waktu duduk, faktor pekerjaan, usia, beban kerja atau masa kerja, kelebihan berat badan (over weight) atau indeks massa tubuh, kebiasaan olah raga. ${ }^{7}$

Sebuah studi mengenai kualitas hidup pada penderita nyeri punggung bawah juga menunjukkan bahwa terdapat penurunan skor kualitas hidup. Kualitas hidup penderita mengalami penurunan yang signifikan yang menunjukkan bahwa bukan hanya komponen fisik saja yang mengalami penurunan tetapi komponen mental juga mengalami penurunan. ${ }^{2}$

Penatalaksanaan nyeri punggung bawah meliputi terapi konservatif (farmakologi, fisioterapi) dan pembedahan. Terapi farmakologi antara lain dengan pemberian obat analgetik non opiat, obat anti inflamasi non steroid, relaksan otot, analgetik opiat, anti depresan, dan anti konvulsan. ${ }^{8}$ Pemberian terapi farmakologi dapat menghilangkan nyeri, akan tetapi dalam jangka panjang dapat menimbulkan efek samping, seperti: gangguan gastrointestinal, perdarahan spontan, hipertensi, thrombosis, dan reaksi alergi. Untuk itu diperlukan terapi alternatif, misalnya akupunktur. Manajemen diri dan akupunktur dapat membantu mengurangi gejala nyeri punggung bawah. ${ }^{9}$ Akupunktur merupakan suatu metode pengobatan dengan menusukkan jarum akupunktur pada titik-titik tertentu di kulit pasien sebagai upaya mengurangi nyeri punggung bawah dan mengobati berbagai keluhan atau permasalahan kesehatan lainnya. ${ }^{4}$ Salah satu metode akupunktur yaitu metode Jin's 3 needle. Jin's 3 needle adalah metode akupunktur dengan menggunakan 3 titik akupunktur sebagai formula utama yang terletak antara lumbal 2 dan 3 bagian kanan dan kiri serta pada pertengahan fosa popliteal. ${ }^{10}$

Tujuan penelitian ini untuk menganalisis pengaruh akupunktur Jin's 3 needle dalam menurunkan intensitas nyeri punggung bawah di Balai Kesehatan Tradisional Sehat Harmoni Indonesia Malang. 


\section{METODE}

Desain penelitian menggunakan preeksperimental design dengan jenis pretestposttest design. Populasi penelitian ini yaitu semua penderita nyeri punggung bawah di Balai Kesehatan Tradisional Sehat Harmoni Indonesia Malang dan sampel yang diambil sebanyak 15 orang. Teknik pengambilan sampel menggunakan teknik total sampling. Kriteria inklusi penelitian yaitu responden yang bersedia diteliti. Kriteria eksklusi penelitian yaitu ibu hamil trimester 1, terdapat bekas luka pada daerah yang akan di tusuk dan responden yang kelelahan. Teknik pengumpulan data dilakukan dengan melakukan informed consent terlebih dahulu kepada responden kemudian hasil pemeriksaan akupunktur dalam menentukan sindrom ginjal defisit dilakukan peneliti melalui pengamatan, wawancara dan palpasi, selanjutnya untuk mengukur intensitas nyeri sebelum diberikan terapi akupunktur Jin's 3 needle, selanjutnya mengukur intensitas nyeri setelah diberikan terapi akupunktur Jin's 3 needle menggunakan dengan kriteria 0 jika tidak nyeri, 1-3 nyeri ringan, 4-6 nyeri sedang, 7-9 nyeri berat dan 10 nyeri tidak tertahankan dengan cara meminta responden untuk memilih intensitas nyeri punggung bawah termasuk kategori yang mana. Intervensi ini diukur dalam kurun waktu 2 bulan dengan frekuensi 3 kali dalam seminggu dan sehari satu kali terapi akupunktur. Peneliti memberikan terapi akupunktur secara terjadwal dengan anggota tim peneliti pada pagi dan sore hari. Selain itu, peneliti juga mengukur variabel lainnya yang menjadi penyebab langsung dan tidak nyeri punggung bawah meliputi jenis kelamin, usia, aktivitas pekerjaan, penggolongan sindrom. Analisis data menggunakan deskriptif frekuensi pada variable karakteristik responden dan uji statistik paired sample $t$ test untuk mengukur intensitas nyeri punggung bawah sebelum dan sesudah intervensi dengan bantuan software SPSS versi 21 . Penelitian ini juga telah dilakukan kaji etik di komite etik STIKes Hafshawaty dengan nomor $\quad$ SK: $\quad$ KEPK/016/STIKesHPZH/II/2018.

\section{HASIL}

Berdasarkan tabel 1. menunjukkan bahwa jenis kelamin penderita nyeri punggung bawah yang terbanyak adalah laki-laki sebanyak 9 orang $(60 \%)$ dan sebanyak 5 orang $(40 \%)$ adalah perempuan; usia penderita nyeri punggung bawah yang terbanyak antara 51-60 tahun sebanyak 6 orang (40\%) dengan penyebab tersering karena kebanyakan duduk sebanyak 8 orang $(65 \%)$ dan penyebab nyeri punggung bawah yang terbanyak berdasarkan penggolongan sindrom karena nyeri punggung bawah ginjal defisit sebanyak 7 orang (47\%). Berdasarkan tabel 2 bahwa sebelum diberikan terapi akupunktur Jin's 3 Needle diketahui intensitas nyeri yang dirasakan penderita nyeri punggung bawah sebanyak 15 penderita meliputi 4 orang mengalami nyeri ringan $(27 \%), 8$ orang mengalami nyeri sedang (53\%), dan 3 orang mengalami nyeri berat (20\%). Setelah diberikan terapi akupunktur Jin's 3 Needle selama 2 bulan dengan dengan frekuensi 3 kali dalam seminggu dan sehari satu kali terapi akupunktur diketahui terdapat penurunan intensitas nyeri yang dirasakan pada semua penderita nyeri punggung bawah sebanyak 15 orang meliputi skala tidak nyeri menjadi sebanyak 2 orang (13\%), pada skala nyeri ringan menjadi sebanyak 9 orang $(60 \%)$, dan pada skala nyeri sedang menjadi sebanyak 4 orang (27\%). Hasil uji Paired $t$ test diperoleh $\mathrm{p}=0.00<\alpha 0.05$. 
Tabel 1. Karakteristik Responden

\begin{tabular}{lc}
\hline Karakteristik $(\mathrm{n}=15)$ & $\mathrm{n}(\%)$ \\
\hline Jenis Kelamin & $9(60)$ \\
Laki-laki & $6(40)$ \\
Perempuan & \\
Usia (tahun) & $5(33)$ \\
$41-50$ & $6(40)$ \\
$51-60$ & $3(20)$ \\
$61-70$ & $1(7)$ \\
$71-80$ & \\
Aktivitas Pekerjaan & $8(65)$ \\
Banyak duduk & $3(24)$ \\
Banyak berdiri & $4(11)$ \\
Banyak bergerak & $2(13)$ \\
Penggolongan sindrom* & $2(13)$ \\
Nyeri punggung bawah lembab dingin*** & $4(27)$ \\
Nyeri punggung bawah lembab panas*** & $7(47)$ \\
Nyeri punggung bawah stasis darah***** & \\
Nyeri punggung bawah ginjal defisit***** &
\end{tabular}

\footnotetext{
* Penggolongan sindrom merujuk kepada ilmu Oriental Medicine

** Nyeri punggung bawah lembab dingin (sering terpapar lembab dan dingin)

*** Nyeri punggung bawah lembab panas (sering terpapar lembab dan panas)

**** Nyeri punggung bawah stasis darah (adanya gumpalan darah pada pembuluh darah)

***** Nyeri punggung bawah ginjal deficit (fungsi ginjal menurun)
}

Tabel 2. Intensitas Nyeri Penderita Nyeri Punggung Bawah Sebelum dan Sesudah Pemberian Terapi Akupunktur Jin's 3 Needle di Balai Kesehatan Tradisional Sehat Harmoni Indonesia Malang

\begin{tabular}{|c|c|c|c|c|c|c|c|c|c|c|c|c|}
\hline \multirow[t]{3}{*}{ Perlakuan } & \multicolumn{10}{|c|}{ Intensitas Nyeri Penderita Nyeri punggung bawah } & \multirow{2}{*}{\multicolumn{2}{|c|}{ Total }} \\
\hline & \multicolumn{2}{|c|}{ Tidak Nyeri } & \multicolumn{2}{|c|}{ Nyeri Ringan } & \multicolumn{2}{|c|}{$\begin{array}{c}\text { Nyeri } \\
\text { Sedang }\end{array}$} & \multicolumn{2}{|c|}{$\begin{array}{l}\text { Nyeri } \\
\text { Berat }\end{array}$} & \multicolumn{2}{|c|}{$\begin{array}{c}\text { Nyeri } \\
\text { Sangat } \\
\text { Berat }\end{array}$} & & \\
\hline & $\mathrm{n}$ & $\%$ & $\mathrm{n}$ & $\%$ & $\mathrm{n}$ & $\%$ & $\mathrm{n}$ & $\%$ & $\mathrm{n}$ & $\%$ & $\mathrm{n}$ & $\%$ \\
\hline Sebelum & 0 & 0 & 4 & 27 & 8 & 53 & 3 & 20 & 0 & 0 & 15 & 100 \\
\hline Sesudah & 2 & 13 & 9 & 60 & 4 & 27 & 0 & 0 & 0 & 0 & 15 & 100 \\
\hline \multicolumn{13}{|c|}{ Paired t test $(\mathrm{p}=0.00<\alpha 0.05)$} \\
\hline
\end{tabular}

\section{PEMBAHASAN}

Nyeri punggung bawah yaitu nyeri atau rasa sakit yang dirasakan seseorang pada tulang belakang daerah spinal (punggung bawah), otot, saraf, tendon, sendi atau tulang rawan. ${ }^{11}$ Faktor penyebab nyeri yaitu jenis kelamin, usia, lama waktu duduk, beban kerja atau masa kerja berhubungan dengan jenis pekerjaan seseorang, kelebihan berat badan serta kebiasaan olah raga. ${ }^{6}$

Upaya yang dilakukan untuk mengobati nyeri yang diderita dengan menggunakan metode farmakologi dan non farmakologi. Metode non farmakologi salah satunya dilakukan dengan terapi akupunktur sebagai upaya pengobatan selain menggunakan obat penghilang nyeri atau sejenisnya yang diketahui memiliki berbagai efek samping. Perangsangan pada titik-titik akupunktur (dengan metode apapun) pada titik meridian, akan mempengaruhi aktivitas otak setelah diakupunktur. Titik yang tepat untuk terapi akupunktur metode Jin's 3 needles yaitu Dachangsu (BL 25) merupakan titik Shu yang terletak di belakang usus besar yang memiliki fungsi salah satunya mengurangi nyeri punggung bawah. ${ }^{12}$ Seseorang yang 
telah diberikan terapi akupunktur jika dilakukan pemeriksaan menggunakan electroenchepalogram akan menurunkan gelombang delta dan tetha yang memberikan efek pada tubuh menjadi rileks. Selain itu, pemberian terapi akupunktur memiliki efek inhibitor pada interneuron di dalam Lamina Rexed $V$ Medulla Spinalis dan inhibisi yang dimediasi oleh Opiate Pain Relieving System. Perubahan aktivitas sel di Cornu Dorsalis Medulla Spinalis juga banyak terjadi selama stimulasi daerah somatik atau viseral, baik berupa stimulasi mekanik, kimia maupun elektris. Perubahan terutama berupa penurunan nyeri. Stimulasi kuat saraf permukaan kulit yang akan dilanjutkan pada Cornu Dorsalis Medulla Spinalis melalui saraf A Delta dan C serta Traktus Spinothalamicus ke arah Thalamus yang akan menghasilkan Endorphin. Hormon inilah yang menyebabkan kondisi tubuh menjadi nyaman sehingga mengurangi nyeri punggung bawah. ${ }^{13}$

Hal ini sesuai dengan hasil penelitian Hutchinson, et all (2012) tentang efektivitas akupunktur dalam mengatasi nyeri punggung bawah kronis non spesifik bahwa akupunktur efektif menghilangkan nyeri setelah terapi rutin selama minimal 8 minggu-3 bulan jika dibandingkan tanpa diberikan pengobatan apapun $^{14}$ dan penelitian lainnya menjelaskan bahwa terapi akupunktur yang efektif menghilangkan nyeri korinis yaitu menggunakan terapi akupunktur standar seperti Jin's 3 neddles pada titik Dachangsu (BL 25) ${ }^{15}$

Berdasarkan hasil penelitian pada tabel 1 bahwa jenis kelamin penderita nyeri punggung bawah terbanyak yaitu laki-laki sebanyak 9 orang $(60 \%)$ dan 5 orang $(40 \%)$ adalah perempuan. Hasil penelitian peneliti tidak sejalan dengan penelitian Wardoyo dan Winarti (2014) tentang Akupunktur Metode Jin's 3 Needles untuk Mengurangi Nyeri Migrain mengatakan bahwa laki-laki dan perempuan memiliki potensi yang sama untuk mengalami nyeri punggung bawah baik laki-laki maupun perempuan sebelum mengalami pubertas memiliki potensi yang sama untuk mengalami nyeri punggung bawah. Prevalensi meningkat setelah masa dewasa awal. Pada perempuan prevalensi nyeri punggung bawah meningkat setelah berakhirnya masa pubertas dan seiring bertambahnya usia karena pengurangan kadar hormon estrogen dalam tubuh. ${ }^{16}$

Hasil penelitian peneliti pada tabel 1 menunjukkan usia penderita nyeri punggung bawah yang terbanyak antara 51-60 tahun sebanyak 6 orang (40\%). Bertambahnya usia dapat meningkatkan risiko nyeri tulang punggung bawah. Hal ini sesuai dengan hasil penelitian Hadyan (2015) bahwa semakin bertambahnya usia akan mengalami penurunan fungsi tubuh terutama tulang sehingga tidak elastis lagi. Kejadian nyeri punggung bawah akan semakin meningkat pada usia setelah 35 tahun. Bertambahnya usia menyebabkan terjadinya degenerasi pada tulang yang selanjutnya akan menimbulkan kerusakan pada jaringan yang dapat membentuk jaringan parut dan menurunkan stabilitas serta elastisitas pada tulang dan otot seseorang. ${ }^{17}$

Selanjutnya faktor pekerjaan seseorang dapat menyebabkan nyeri punggung bawah. Sesuai hasil penelitian peneliti pada tabel 1 bahwa penyebab tersering nyeri punggung bawah karena kebanyakan duduk sebanyak 8 orang $(65 \%)$. Aktifitas sering duduk di alami oleh seseorang yang berprofesi sebagai supir, penjahit, pekerja kantoran dan lainnya. Hal ini sejalan dengan penelitian Ahmad dan Budiman (2014) bahwa posisi duduk yang tidak ergonomis, lama waktu duduk dan aktifitas yang berlebihan dapat menyebabkan nyeri punggung bawah karena ketegangan otot dengan lokasi nyeri yang sering dialami yaitu daerah lumbo sakral dan sakro iliaka. ${ }^{8,17 .}$

Faktor lainnya yang mempengaruhi nyeri punggung bawah yaitu karena sindrom ginjal defisit (sebuah sindrom menurut ilmu Oriental Medicine yang 
menyatakan adanya kekurangan substansi vital dalam organ ginjal sehingga menimbulkan ketegangan otot daerah punggung bawah).. Hasil penelitian pada tabel 1 menunjukkan bahwa penyebab nyeri punggung bawah karena sindrom nyeri punggung bawah ginjal defisit sebanyak 7 orang $(47 \%)$. Hal ini sesuai dengan hasil penelitian Aszar, Imandiri, dan Mustika bahwa sindrom ginjal defisit menjadi salah satu penyebab nyeri punggung bawah dan upaya yang dilakukan dengan menggunakan metode akupunktur diketahui efektif meningkatkan fungsi ginjal dengan cara mengubah stagnasi dan meredakan nyeri. ${ }^{12}$ Hal ini sejalan dengan penelitian Zhu, et all (2014) bahwa akupunktur dapat menjadi terapi alternatif dalam mengurangi nyeri persendian termasuk pergelangan kaki yang penyebabnya sama dengan nyeri punggung bawah ${ }^{18}$ dan dipertegas dengan penelitian tentang "Systematic Review and Meta-Analysis of Effects of Acupuncture on Pain and Function in Non-Specific Low Back Pain" bahwa terapi akupunktur hanya efektif untuk menghilangkan nyeri punggung bawah non spesifik. ${ }^{19}$

Namun, hasil penelitian lainnya menjelaskan bahwa akupunktur tidak efektif jika perawatan yang diberikan kurang dari 2 atau 3 bulan dalam mengatasi nyeri punggung bawah dan faktor penentu keberhasilan lainnya yaitu kedalaman tusukan jarum akupunktur, frekuensi, penempatan penyisipan jarum dan apakah stimulasi jarum mencapai De Qi atau titik akupunktur yang diharapkan. ${ }^{20}$

\section{KESIMPULAN}

Teknik Akupunktur Jin's 3 needle dapat menurunkan intensitas nyeri penderita nyeri punggung bawah di Balai Kesehatan Tradisional Sehat Harmoni Indonesia Malang. Oleh karena itu, terapi akupunktur dapat dilakukan sebagai metode alternatif non farmakologi untuk mengurangi keluhan nyeri punggung bawah. Penelitian ini terdapat keterbatasan dari segi metode, dimana peneliti hanya mengukur satu kali sebelum intervensi dan satu kali setelah diberikan intervensi selama 2 bulan dengan frekuensi 3 kali seminggu dan 1 kali dalam sehari dan tidak terdapat kelompok pembanding yang tidak diberikan terapi akupunktur.

Saran untuk peneliti selanjutnya agar hasil penelitian lebih valid yaitu dengan menambahkan kelompok pembanding penelitian serta pengukuran setelah intervensi dialkukan minimal 3-4 kali untuk melihat konsistensi hasil terapi akupunktur Jin's 3 needle yang diberikan dalam menurunkan intensitas nyeri punggung bawah.

\section{DAFTAR PUSTAKA}

1. Arwino LD. Keluhan Nyeri Punggung Bawah pada Penjahit Garmen. Higeia Journal of Public Health Research and Development. 2018;2(3):406-16.

2. Hong JH, Kim HD, Shin HH, Huh B. Assessment of depression, anxiety, sleep disturbance, and quality of life in patients with chronic low back pain in Korea. Korean Journal Anesthesiol. 2014;66(6):444-50.

3. Hoy D, March L, Brooks P, Blyth F, Woolf A, Bain C, et al. The global burden of low back pain: Estimates from the Global Burden of Disease 2010 study. Annals of Rheumatic Diseases. 2014;73(6):968-74.

4. Hidayat IT. Pengaruh Akupunktur Pergelangan Tangan dan Pergelangan Kaki Terhadap Skor Numeric Analog Scale Pada Pasien Nyeri Punggung Bawah dibandingkan dengan Akupunktur Tubuh. Universitas Indonesia; Jakarta. 2014.

5. Liu L, Skinner MA, McDonough SM, Baxter GD. Acupuncture for chronic low back pain: a randomized controlled feasibility trial comparing treatment session numbers. Clinical Rehabilitation. 2017;31(12):1-12.

6. Purnamasari, H; Gunarso, U; Rujito, 
L. Overweight Sebagai Faktor Resiko Low Back Pain Pada Pasien. Mandala of Health. 2010;4(1):26-32.

7. Ahmad A, Budiman F. Hubungan Posisi Duduk dengan Nyeri Punggung Bawah pada Penjahit Vermak Levis di Pasar Tanah Pasir Kelurahan Penjaringan Jakarta Utara Tahun 2014. Forum Ilmiah. 2014;11(3):412-20.

8. Purba, JS. Patofisiologi dan Penatalaksanaan Nyeri - Suatu Tinjauan Seluler dan Biologi Molekuler. Balai Penerbit Fakultas Kedokteran Universitas Indonesia, Jakarta. 2010.

9. Cheshire A, Polley M., Peters D, Ridge DT. Patient outcomes and experiences of an acupuncture and self-care service for persistent low back pain in the NHS: a mixed methods approach. BMC Complementary and Alternative Medicine [Internet]. 2013;13(1):300. Available from:

https://westminsterresearch.westminst er.ac.uk/item/8yz1z/patient-outcomesand-experiences-of-an-acupunctureand-self-care-service-for-persistentlow-back-pain-in-the-nhs-a-mixedmethods-approach

10. Saputra, K. Akupunktur Indonesia Edisi 2. Airlangga University Press, Surabaya. 2017.

11. Riningrum H, Widowati E. Pengaruh Sikap Kerja, Usia, dan Masa Kerja Terhadap Keluhan Low Back Pain. Jurnal Pena Medika. 2016;6(2):91102.

12. Aszar FDD, Imandiri A, Mustika A. Therapy for low back pain with acupunture and turmeric. Journal Vocational Health Study [Internet]. 2018;02(01):74-9. Available from: www.ejournal.unair.ac.id/index.php/JVHS

13. Purwanto, Purwandari $\mathrm{H}$, Arfianto MA. Pengaruh Terapi Akupunktur Terhadap Penurunan Tingkat Nyeri
Pasien Low Back Pain (LBP) di Polineurologi RSUD dr. Harjono ponorogo. Repository Strada Jurnal Ilmiah Kesehatan [Internet]. 2015. Available from: https://onesearch.id/Record/IOS5196. article-26. Diakses tanggal 12 Maret 2020.

14. Hutchinson AJP, Ball S, Andrews JCH, Jones GG. The effectiveness of acupuncture in treating chronic nonspecific low back pain: A systematic review of the literature. Journal of Orthopaedic Surgery and Research [Internet]. 2012;7(1):1. Available from: Journal of Orthopaedic Surgery and Research

15. Pach D, Yang-Strobel $X$, Lüdtke R, Roll S, Icke K, Brinkhaus B, et al. Standardized versus individualized acupuncture for chronic low back pain: A randomized controlled trial. Evidence-based Complementary Alternative Medicine. 2013;2013

16. Wardoyo P, Winarti IT. Akupunktur Metode Jin'S 3 Needles Untuk Mengurangi Nyeri Migrain. Jurnal Kesehatan Hesti Wira Sakti. 2014;3(3):50-6.

17. Hadyan MF. Faktor - Faktor yang Mempengaruhi Kejadian Low Back Pain pada Pengemudi Transportasi Publik. Majority. 2015;4(7):19-24.

18. Zhu LB, Chan WC, Lo KC, Yum TP, Li L. Wrist-ankle acupuncture for the treatment of pain symptoms: A systematic review and meta-analysis. Evidence-based Complementary Alternative Medicine. 2014;2014.

19. Li YX, Yuan SE, Jiang JQ, Li H, Wang YJ. Systematic review and meta-analysis of effects of acupuncture on pain and function in non-specific low back pain. Acupuncture in Medicine. 2020;38(4):235-43.

20. Zeng Y, Chung JWY. Acupuncture for chronic nonspecific low back pain: An overview of systematic reviews. European Journal of Integrative 
Abdullah, et al.

Medicine [Internet]. 2015;7(2):94-

http://dx.doi.org/10.1016/j.eujim.2014.

107.

Available

from:

11.001 